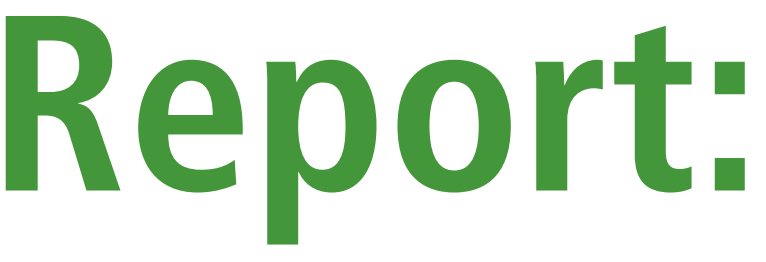

\title{
2006-based marital status and cohabitation projections for England \& Wales
}

\section{Introduction}

The Office for National Statistics (ONS) published the 2006-based marital status projections for England and Wales on 31 March $2009^{1}$. These cover both legal marital status and cohabitation ${ }^{2}$ and are the first set of marital status projections to adjust for marriages to England and Wales residents taking place abroad ${ }^{3}$. The results of the projections are available to 2031 and replace the 2003-based projections published by the Government Actuaries Department (GAD) ${ }^{4}$; responsibility for the projections transferred to the ONS in 2006. The new marital status projections are fully consistent with the 2006-based national population projections (by age and sex) for England and Wales published in October $2007^{5}$. They also incorporate new estimates of the population by legal marital status ${ }^{6}$ and the population cohabiting ${ }^{7}$ as at the middle of 2007. For this reason, all data tables start at mid-2007.

One of the main uses of these projections is as an input to the regular projections of the number, and type, of households in England, produced by Communities and Local Government ${ }^{8}$. Marital status projections are also used by the Department for Work and Pensions to cost various aspects of the future social security programme.

\section{Assumptions}

The legal marital status projections are produced using a component methodology ${ }^{9}$ that uses assumptions of the underlying marriage, remarriage and divorce rates based on recent trends. The cohabitation projection uses assumptions about the proportions cohabiting and applies these to the results of the legal marital status projections. A group of experts were consulted on the assumptions used.

Marriage rates for the past five years were extrapolated forward, but trends were assumed to diminish gradually, with projected rates held constant from $2017^{10}$. The past five years was a shorter series than used in previous projections, as estimates for marriages taking place abroad are not available for years before 2002. Similarly divorce rates for the past ten years were extrapolated forward but with trends assumed to diminish gradually, with projected rates held constant from $2017^{11}$.
For marriages, the assumptions made are that marriage rates for under 30 -year-olds will continue to fall over the next ten years, as seen over the last decade, but at older ages rates will either remain similar to those presently observed or increase slightly. For divorces, it is assumed that rates will not change much for under those aged under 35 , but that rates will continue to rise at ages over 40 .

Establishing the underlying trend in opposite sex cohabitation is more difficult as there is not a consistent series of estimates of the cohabiting population of England and Wales. However, estimates of proportions cohabiting can be obtained from periodic estimates of the cohabiting population in England and Wales ${ }^{7}$. These show a continued increase in the proportion of the population cohabiting for people aged over 30 that have never been married, but there is no clear evidence of changing levels of cohabitation for other ages or marital states. Thus the proportion of people who cohabit is assumed to rise for single (never married) people aged over 30 , but to remain constant for all other marital status and age groups ${ }^{12}$.

As noted above, the marital status projections are consistent with the 2006-based national population projections for England and Wales. Therefore, the total number of deaths and the total number of net migrants each year are constrained to agree, for each age and sex, with the national projection. Assumptions about the distribution by marital status have to be made for these deaths and migrants. Mortality rates in England and Wales, as in other countries, are consistently lower for married people than for never married or previously married individuals. These mortality differentials have changed little in recent years, so it has been assumed that current mortality differentials by marital status remain constant throughout the projection period ${ }^{13}$. For net migration, an assumed marital status distribution has been derived from the distributions used by ONS in the preparation of its mid-year population estimates by marital status ${ }^{14}$.

\section{Consistency constraints}

The marital status projections are subject to a number of constraints ${ }^{15}$, both external (for example agreeing with the national population projections) and internal (such as an equal number of divorces to men 


\section{Box one}

\section{Consistency constraints of the projection model}

Typically, a marital status projection will be subject to a number of external and internal constraints ${ }^{15}$. Within these constraints, the projections will be determined by assumptions of future marriage and remarriage rates, divorce rates, mortality differentials by marital status and net migration by marital status.

\section{External constraints}

The marital status projections were constrained to agree with the 2006-based national (age and sex) projections for England and Wales.

\section{Internal constraints}

The 'input rates' for marriage and divorce described in the main text were subject to further adjustment in order to satisfy the following standard two-sex consistency requirements:

(a) the number of males divorcing must equal the number of females divorcing

(b) the number of married males dying must equal the number of females becoming widowed, and

(c) the number of married females dying must equal the number of males becoming widowed

Note, however, that as one partner in a marriage may be temporarily resident abroad, the number of married men and women are never exactly equal in population estimates and have not been constrained to be equal in these projections.

\section{Cohabitation}

As noted above, the estimated numbers of married men and women are never exactly equal, and have not been constrained to be equal in the legal marital status projections. A similar argument could apply to the cohabiting population, but the available data does not allow an accurate estimate to be made of any imbalance. Therefore, both the base year population estimates produced by ONS and these projections have been constrained so that the total number of cohabiting males equals the total number of cohabiting females.

and women). More detail of these constraints can be found in Box One. As a consequence of including an adjustment for marriages taking place abroad, two changes have been made to the consistency constraints compared to those used for the 2003-based projection. Firstly, it is no longer assumed that the number of married males and females entering the country are equal. Secondly, it is no longer assumed that there are an equal number of marriages of males and females each year.

\section{Legal marital status results}

\section{Principal projection}

The 2006-based population projections by legal marital status for England and Wales can be seen for 2007 and selected years to 2031 in Table 1 .

The proportion of the adult ${ }^{16}$ population who are married is projected to fall from 51 per cent in 2007 to 42 per cent in 2031 for males, and from 48 per cent to 41 per cent for females. The actual number projected to be married changes little due to the expected increase in the adult population over the period in question.

The falling marriage rates for those aged under 30 observed in the past, and expected to continue in the short term, have an impact over the course of the projection period. In addition to the immediate effect on the proportions of those under 30 being married it also has an impact at older ages. Thus over the period to 2031 there is expected to be a fall in the married population aged less than 65 , and a corresponding increase in the never married population. The proportion of men aged between 45 and 54 who have never been married is projected to more than double between 2007 and 2031 rising from 16 per cent to 35 per cent, and for men aged between 55 and 64 from 9 per cent to 25 per cent. Similarly, for never married women at the same ages, proportions are projected to increase more than threefold.

The proportion of the adult population who are divorced is projected to increase slightly between 2007 and 2031, from 8 to 9 per cent for males and from 10 to 12 per cent for females. However, patterns for each age group are mixed; between 2007 and 2031 the proportion of divorced men aged between 35 and 44 is projected to decrease from 10 per cent to 7 per cent, and for women of the same ages from 14 to 10 per cent. This is partly due to the falling size in the married population at these ages, which therefore reduces the number of people who are at risk of divorce. At ages 45 to 64, the proportion of the population that are divorced will rise to a peak around 2021 and then start to fall. The most significant increase is in the oldest age group of 65 and over, where the number divorced is expected to more than double from 7 per cent in 2007 to 14 per cent in 2031 for males, and from 8 per cent to 17 per cent for females. At younger ages, the proportion of adults who are divorced is projected to fall gradually from 2007.

Results are affected by other demographic factors as well as trends in marriage and divorce. For example, as mortality continues to improve, particularly at older ages, the proportion of both sexes who are widowed reduces. The proportion of women aged 75 and over who are widowed is projected to fall from 61 per cent in 2007 to 40 per cent in 2031. The number of males who are widowed is lower, as might be expected due to higher female life expectancy, but the proportion aged 75 and over projected to be widowed also drops from 26 per cent in 2007 to 19 per cent in 2031.

The projected change in the composition of the population by legal marital status is clearly shown in the pyramids for 2007 and 2031 in Figure 1 (an animated series of population pyramids is available from the ONS website ${ }^{17}$ ). Comparing these pyramids shows how both the size and average age of the population as a whole is projected to increase. It also shows that the number remaining never married is projected to stay high at younger ages, and to increase considerably at older ages, with a corresponding reduction in the proportion married. The increase in the proportion divorced at older ages can also be clearly seen.

\section{Variant projections}

Population projections are, of course, subject to uncertainty. Inevitably, actual trends in marriage and divorce will differ, to a greater or lesser extent, from those assumed in the principal projections. To give an indication of the underlying uncertainty, variant projections have been produced based on alternative assumptions about the future levels of marriage and divorce. In these variants, marriage and divorce rates are applied which gradually diverge from those assumed in the principal projection until, from 2021 onwards, assumed first marriage and divorce rates differ by $+/-15$ per cent from the principal projection and assumed remarriage rates differ by $+/-10$ per cent.

Summary results of all the variant projections by legal marital status are shown in Table 2. In terms of numbers of people, the high marriage 
Table 1

Estimated and projected population by legal marital status, age and sex, 1991-2031

England and Wales

2006-based marital status projections

\begin{tabular}{|c|c|c|c|c|c|c|c|c|c|c|c|}
\hline & & \multicolumn{5}{|c|}{ Number (thousands) } & \multicolumn{5}{|c|}{ Percentages } \\
\hline & & Total & Never married & Married & Widowed & Divorced & Total & Never married & Married & Widowed & Divorced \\
\hline \multicolumn{12}{|l|}{ Males } \\
\hline \multirow[t]{6}{*}{ All 16 plus } & 1991 & 19,441 & 5,891 & 11,636 & 727 & 1,187 & 100 & 30 & 60 & 4 & 6 \\
\hline & 2001 & 20,198 & 6,894 & 11,090 & 733 & 1,482 & 100 & 34 & 55 & 4 & 7 \\
\hline & 2007 & 21,338 & 8,049 & 10,851 & 715 & 1,724 & 100 & 38 & 51 & 3 & 8 \\
\hline & 2011 & 22,174 & 8,811 & 10,799 & 717 & 1,848 & 100 & 40 & 49 & 3 & 8 \\
\hline & 2021 & 23,894 & 10,196 & 10,765 & 755 & 2,179 & 100 & 43 & 45 & 3 & 9 \\
\hline & 2031 & 25,745 & 11,682 & 10,882 & 817 & 2,364 & 100 & 45 & 42 & 3 & 9 \\
\hline \multirow[t]{6}{*}{$16-24$} & 1991 & 3,336 & 3,074 & 250 & 0 & 12 & 100 & 92 & 8 & 0 & 0 \\
\hline & 2001 & 2,891 & 2,806 & 80 & 1 & 4 & 100 & 97 & 3 & 0 & 0 \\
\hline & 2007 & 3,357 & 3,287 & 66 & 1 & 3 & 100 & 98 & 2 & 0 & 0 \\
\hline & 2011 & 3,415 & 3,361 & 52 & 0 & 2 & 100 & 98 & 2 & 0 & 0 \\
\hline & 2021 & 3,111 & 3,071 & 39 & 0 & 1 & 100 & 99 & 1 & 0 & 0 \\
\hline & 2031 & 3,520 & 3,477 & 42 & 0 & 1 & 100 & 99 & 1 & 0 & 0 \\
\hline \multirow[t]{6}{*}{$25-34$} & 1991 & 3,920 & 1,652 & 2,028 & 2 & 237 & 100 & 42 & 52 & 0 & 6 \\
\hline & 2001 & 3,758 & 2,227 & 1,391 & 3 & 136 & 100 & 59 & 37 & 0 & 4 \\
\hline & 2007 & 3,509 & 2,384 & 1,027 & 3 & 96 & 100 & 68 & 29 & 0 & 3 \\
\hline & 2011 & 3,779 & 2,741 & 955 & 3 & 81 & 100 & 73 & 25 & 0 & 2 \\
\hline & 2021 & 4,300 & 3,304 & 924 & 1 & 71 & 100 & 77 & 21 & 0 & 2 \\
\hline & 2031 & 4,004 & 3,095 & 846 & 1 & 63 & 100 & 77 & 21 & 0 & 2 \\
\hline \multirow[t]{6}{*}{$35-44$} & 1991 & 3,504 & 477 & 2,632 & 11 & 384 & 100 & 14 & 75 & 0 & 11 \\
\hline & 2001 & 3,881 & 963 & 2,494 & 12 & 411 & 100 & 25 & 64 & 0 & 11 \\
\hline & 2007 & 4,076 & 1,259 & 2,385 & 10 & 422 & 100 & 31 & 59 & 0 & 10 \\
\hline & 2011 & 3,853 & 1,342 & 2,135 & 9 & 367 & 100 & 35 & 55 & 0 & 10 \\
\hline & 2021 & 3,870 & 1,737 & 1,830 & 6 & 297 & 100 & 45 & 47 & 0 & 8 \\
\hline & 2031 & 4,388 & 2,110 & 1,969 & 5 & 305 & 100 & 48 & 45 & 0 & 7 \\
\hline \multirow[t]{6}{*}{$45-54$} & 1991 & 2,919 & 251 & 2,347 & 31 & 290 & 100 & 9 & 80 & 1 & 10 \\
\hline & 2001 & 3,415 & 419 & 2,511 & 37 & 448 & 100 & 12 & 74 & 1 & 13 \\
\hline & 2007 & 3,475 & 563 & 2,365 & 30 & 519 & 100 & 16 & 68 & 1 & 15 \\
\hline & 2011 & 3,801 & 734 & 2,459 & 28 & 581 & 100 & 19 & 65 & 1 & 15 \\
\hline & 2021 & 3,771 & 1,033 & 2,150 & 20 & 568 & 100 & 27 & 57 & 1 & 15 \\
\hline & 2031 & 3,798 & 1,339 & 1,953 & 15 & 491 & 100 & 35 & 51 & 0 & 13 \\
\hline \multirow[t]{6}{*}{$55-64$} & 1991 & 2,514 & 205 & 2,047 & 96 & 165 & 100 & 8 & 81 & 4 & 7 \\
\hline & 2001 & 2,744 & 225 & 2,136 & 84 & 299 & 100 & 8 & 78 & 3 & 11 \\
\hline & 2007 & 3,146 & 294 & 2,351 & 85 & 417 & 100 & 9 & 75 & 3 & 13 \\
\hline & 2011 & 3,176 & 344 & 2,286 & 79 & 467 & 100 & 11 & 72 & 2 & 15 \\
\hline & 2021 & 3,582 & 615 & 2,282 & 62 & 623 & 100 & 17 & 64 & 2 & 17 \\
\hline & 2031 & 3,565 & 879 & 2,048 & 48 & 590 & 100 & 25 & 57 & 1 & 17 \\
\hline \multirow[t]{6}{*}{$65-74$} & 1991 & 2,027 & 150 & 1,574 & 229 & 74 & 100 & 7 & 78 & 11 & 4 \\
\hline & 2001 & 2,052 & 155 & 1,569 & 188 & 139 & 100 & 8 & 76 & 9 & 7 \\
\hline & 2007 & 2,127 & 150 & 1,620 & 162 & 196 & 100 & 7 & 76 & 8 & 9 \\
\hline & 2011 & 2,342 & 168 & 1,762 & 160 & 252 & 100 & 7 & 75 & 7 & 11 \\
\hline & 2021 & 2,792 & 273 & 1,963 & 154 & 402 & 100 & 10 & 70 & 6 & 14 \\
\hline & 2031 & 3,202 & 507 & 2,036 & 130 & 530 & 100 & 16 & 64 & 4 & 17 \\
\hline \multirow[t]{6}{*}{75 plus } & 1991 & 1,221 & 81 & 759 & 357 & 25 & 100 & 7 & 62 & 29 & 2 \\
\hline & 2001 & 1,458 & 99 & 909 & 407 & 44 & 100 & 7 & 62 & 28 & 3 \\
\hline & 2007 & 1,649 & 114 & 1,038 & 425 & 72 & 100 & 7 & 63 & 26 & 4 \\
\hline & 2011 & 1,809 & 121 & 1,150 & 438 & 99 & 100 & 7 & 64 & 24 & 5 \\
\hline & 2021 & 2,470 & 164 & 1,577 & 511 & 217 & 100 & 7 & 64 & 21 & 9 \\
\hline & 2031 & 3,268 & 276 & 1,989 & 618 & 385 & 100 & 8 & 61 & 19 & 12 \\
\hline
\end{tabular}

Source: Office for National Statistics 
Table 1

continued

Estimated and projected population by legal marital status, age and sex, 1991-2031

England and Wales

2006-based marital status projections

\begin{tabular}{|c|c|c|c|c|c|c|c|c|c|c|c|}
\hline & & \multicolumn{5}{|c|}{ Number (thousands) } & \multicolumn{5}{|c|}{ Percentages } \\
\hline & & Total & Never married & Married & Widowed & Divorced & Total & Never married & Married & Widowed & Divorced \\
\hline \multicolumn{12}{|l|}{ Females } \\
\hline \multirow[t]{6}{*}{ All 16 plus } & 1991 & 21,060 & 4,817 & 11,833 & 2,951 & 1,459 & 100 & 23 & 56 & 14 & 7 \\
\hline & 2001 & 21,667 & 5,798 & 11,150 & 2,745 & 1,975 & 100 & 27 & 51 & 13 & 9 \\
\hline & 2007 & 22,521 & 6,871 & 10,851 & 2,511 & 2,289 & 100 & 31 & 48 & 11 & 10 \\
\hline & 2011 & 23,201 & 7,604 & 10,775 & 2,365 & 2,457 & 100 & 33 & 46 & 10 & 11 \\
\hline & 2021 & 24,660 & 8,892 & 10,733 & 2,149 & 2,886 & 100 & 36 & 44 & 9 & 12 \\
\hline & 2031 & 26,440 & 10,402 & 10,745 & 2,140 & 3,154 & 100 & 39 & 41 & 8 & 12 \\
\hline \multirow[t]{6}{*}{$16-24$} & 1991 & 3,240 & 2,688 & 522 & 1 & 30 & 100 & 83 & 16 & 0 & 1 \\
\hline & 2001 & 2,833 & 2,627 & 194 & 2 & 9 & 100 & 93 & 7 & 0 & 0 \\
\hline & 2007 & 3,166 & 3,016 & 142 & 1 & 6 & 100 & 95 & 4 & 0 & 0 \\
\hline & 2011 & 3,206 & 3,089 & 112 & 0 & 4 & 100 & 96 & 3 & 0 & 0 \\
\hline & 2021 & 2,919 & 2,830 & 85 & 0 & 3 & 100 & 97 & 3 & 0 & 0 \\
\hline & 2031 & 3,323 & 3,228 & 91 & 0 & 4 & 100 & 97 & 3 & 0 & 0 \\
\hline \multirow[t]{6}{*}{$25-34$} & 1991 & 3,943 & 1,135 & 2,488 & 8 & 312 & 100 & 29 & 63 & 0 & 8 \\
\hline & 2001 & 3,778 & 1,770 & 1,768 & 10 & 231 & 100 & 47 & 47 & 0 & 6 \\
\hline & 2007 & 3,490 & 2,000 & 1,326 & 7 & 158 & 100 & 57 & 38 & 0 & 5 \\
\hline & 2011 & 3,745 & 2,338 & 1,262 & 6 & 139 & 100 & 62 & 34 & 0 & 4 \\
\hline & 2021 & 4,127 & 2,801 & 1,200 & 3 & 123 & 100 & 68 & 29 & 0 & 3 \\
\hline & 2031 & 3,847 & 2,637 & 1,098 & 3 & 110 & 100 & 69 & 29 & 0 & 3 \\
\hline \multirow[t]{6}{*}{$35-44$} & 1991 & 3,517 & 280 & 2,760 & 34 & 444 & 100 & 8 & 78 & 1 & 13 \\
\hline & 2001 & 3,935 & 692 & 2,649 & 36 & 558 & 100 & 18 & 67 & 1 & 14 \\
\hline & 2007 & 4,132 & 1,004 & 2,525 & 29 & 574 & 100 & 24 & 61 & 1 & 14 \\
\hline & 2011 & 3,882 & 1,120 & 2,242 & 23 & 497 & 100 & 29 & 58 & 1 & 13 \\
\hline & 2021 & 3,861 & 1,493 & 1,945 & 15 & 407 & 100 & 39 & 50 & 0 & 11 \\
\hline & 2031 & 4,241 & 1,808 & 2,015 & 12 & 406 & 100 & 43 & 48 & 0 & 10 \\
\hline \multirow[t]{6}{*}{$45-54$} & 1991 & 2,915 & 144 & 2,322 & 118 & 332 & 100 & 5 & 80 & 4 & 11 \\
\hline & 2001 & 3,471 & 256 & 2,548 & 111 & 557 & 100 & 7 & 73 & 3 & 16 \\
\hline & 2007 & 3,551 & 397 & 2,413 & 87 & 654 & 100 & 11 & 68 & 2 & 18 \\
\hline & 2011 & 3,884 & 566 & 2,501 & 79 & 738 & 100 & 15 & 64 & 2 & 19 \\
\hline & 2021 & 3,835 & 926 & 2,148 & 52 & 710 & 100 & 24 & 56 & 1 & 19 \\
\hline & 2031 & 3,821 & 1,234 & 1,936 & 36 & 615 & 100 & 32 & 51 & 1 & 16 \\
\hline \multirow[t]{6}{*}{$55-64$} & 1991 & 2,613 & 149 & 1,889 & 385 & 189 & 100 & 6 & 72 & 15 & 7 \\
\hline & 2001 & 2,817 & 135 & 2,031 & 291 & 361 & 100 & 5 & 72 & 10 & 13 \\
\hline & 2007 & 3,267 & 179 & 2,306 & 260 & 522 & 100 & 5 & 71 & 8 & 16 \\
\hline & 2011 & 3,307 & 224 & 2,266 & 231 & 586 & 100 & 7 & 69 & 7 & 18 \\
\hline & 2021 & 3,731 & 501 & 2,288 & 166 & 776 & 100 & 13 & 61 & 4 & 21 \\
\hline & 2031 & 3,692 & 826 & 2,015 & 120 & 731 & 100 & 22 & 55 & 3 & 20 \\
\hline \multirow[t]{6}{*}{$65-74$} & 1991 & 2,479 & 176 & 1,317 & 879 & 107 & 100 & 7 & 53 & 35 & 4 \\
\hline & 2001 & 2,326 & 130 & 1,322 & 697 & 177 & 100 & 6 & 57 & 30 & 8 \\
\hline & 2007 & 2,342 & 111 & 1,410 & 563 & 257 & 100 & 5 & 60 & 24 & 11 \\
\hline & 2011 & 2,549 & 115 & 1,580 & 519 & 335 & 100 & 5 & 62 & 20 & 13 \\
\hline & 2021 & 3,039 & 195 & 1,862 & 444 & 538 & 100 & 6 & 61 & 15 & 18 \\
\hline & 2031 & 3,471 & 445 & 1,963 & 354 & 709 & 100 & 13 & 57 & 10 & 20 \\
\hline \multirow[t]{6}{*}{75 plus } & 1991 & 2,353 & 246 & 536 & 1,526 & 46 & 100 & 10 & 23 & 65 & 2 \\
\hline & 2001 & 2,506 & 188 & 639 & 1,598 & 81 & 100 & 7 & 25 & 64 & 3 \\
\hline & 2007 & 2,573 & 163 & 728 & 1,564 & 118 & 100 & 6 & 28 & 61 & 5 \\
\hline & 2011 & 2,628 & 151 & 812 & 1,507 & 158 & 100 & 6 & 31 & 57 & 6 \\
\hline & 2021 & 3,149 & 146 & 1,204 & 1,470 & 330 & 100 & 5 & 38 & 47 & 10 \\
\hline & 2031 & 4,045 & 225 & 1,627 & 1,616 & 578 & 100 & 6 & 40 & 40 & 14 \\
\hline
\end{tabular}


England and Wales

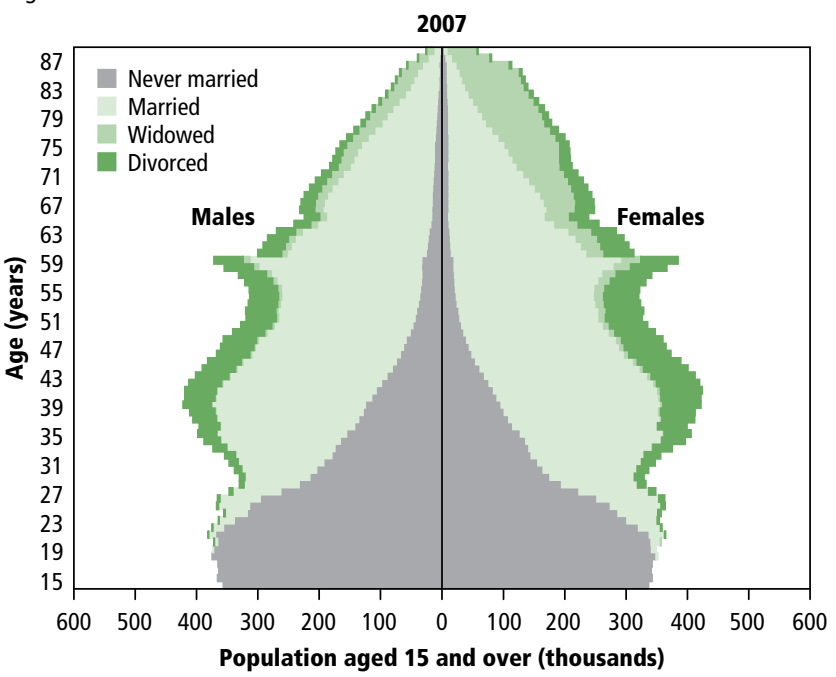

Source: Office for National Statistics

\section{Table 2}

England and Wales

2006-based marital status projections

\begin{tabular}{|c|c|c|c|c|c|}
\hline & \multicolumn{5}{|c|}{ Population aged 16 and over } \\
\hline & Total & Never married & Married & Widowed & Divorced \\
\hline \multicolumn{6}{|l|}{ Estimate } \\
\hline 2007 & 43,860 & 14,920 & 21,702 & 3,226 & 4,012 \\
\hline \multicolumn{6}{|l|}{ Principal } \\
\hline 2011 & 45,375 & 16,415 & 21,574 & 3,082 & 4,305 \\
\hline 2021 & 48,554 & 19,087 & 21,498 & 2,904 & 5,065 \\
\hline 2031 & 52,185 & 22,084 & 21,627 & 2,957 & 5,517 \\
\hline \multicolumn{6}{|c|}{ High marriage } \\
\hline 2011 & 45,375 & 16,377 & 21,619 & 3,081 & 4,298 \\
\hline 2021 & 48,554 & 18,700 & 21,925 & 2,901 & 5,028 \\
\hline 2031 & 52,185 & 21,220 & 22,512 & 2,960 & 5,493 \\
\hline \multicolumn{6}{|c|}{ Low marriage } \\
\hline 2011 & 45,375 & 16,453 & 21,528 & 3,082 & 4,312 \\
\hline 2021 & 48,554 & 19,489 & 21,056 & 2,907 & 5,101 \\
\hline 2031 & 52,185 & 23,016 & 20,681 & 2,955 & 5,533 \\
\hline \multicolumn{6}{|c|}{ High divorce } \\
\hline 2011 & 45,375 & 16,415 & 21,550 & 3,082 & 4,329 \\
\hline 2021 & 48,554 & 19,088 & 21,291 & 2,901 & 5,274 \\
\hline 2031 & 52,185 & 22,086 & 21,230 & 2,945 & 5,923 \\
\hline \multicolumn{6}{|c|}{ Low divorce } \\
\hline 2011 & 45,375 & 16,415 & 21,598 & 3,082 & 4,281 \\
\hline 2021 & 48,554 & 19,087 & 21,708 & 2,907 & 4,852 \\
\hline 2031 & 52,185 & 22,082 & 22,036 & 2,970 & 5,098 \\
\hline
\end{tabular}

Source: Office for National Statistics

and low divorce variants both show very slight increases in the expected numbers of married people by 2031 compared to 2007. But even the high marriage variant shows that over time the proportion of the adult population that are expected to be married will fall from 49 per cent in 2007 to 43 per cent in 2031, compared to 41 per cent for the principal projection and 40 per cent for the low marriage variant. In all projections the size of the never married population increases significantly.

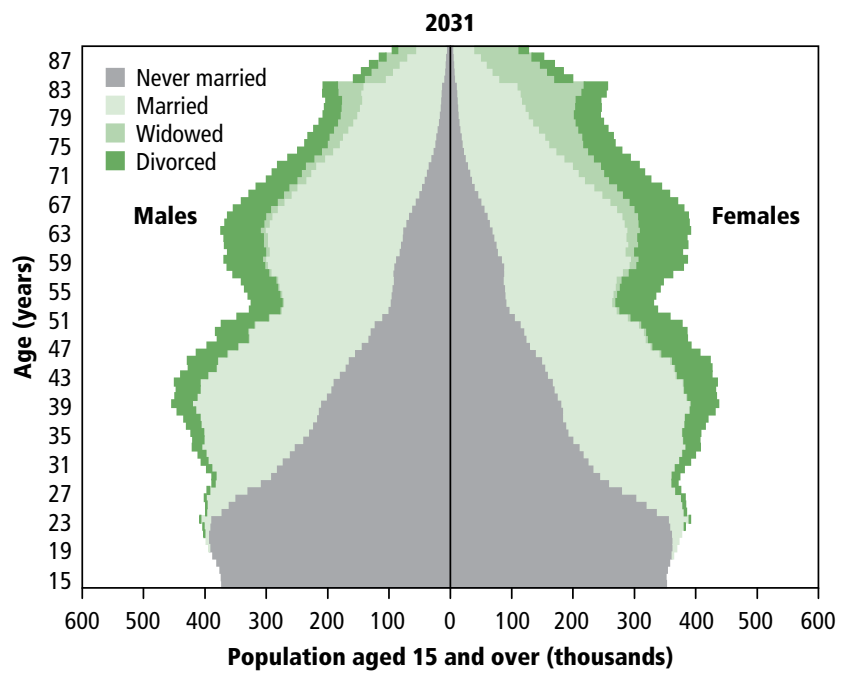

The size of the divorced population is projected to increase over the period of the projection for all the variants, including the low divorce variant. In 2007 the divorced adult population was estimated to be 4.0 million; the low divorce variant projects this to increase to 5.1 million by 2031, compared to 5.5 million for the principal projection and 5.9 million for the high divorce variant. This is mainly an effect of the ageing of those currently aged 35 to 54 who have been exposed to recent high divorce rates.

There are a number of complex interactions at work within these variants. A higher number of people getting married will, of course, reduce the number of people who remain never married. However, the knock-on effects on the divorced and widowed populations are less straightforward. A higher marriage rate assumption increases the number of married people and therefore increases the number at risk of divorce or widowhood. However, this is offset by an increase in the proportion assumed to remarry.

\section{Cohabitation results}

Projections by legal marital status alone are insufficient to give a full picture of the partnership status of the population of England and Wales due to the increasing occurrence of cohabitation, either as a prelude to marriage or as an alternative. ONS therefore has also produced 2006-based cohabitation projections by legal marital status.

\section{Principal projection}

The results of the principal cohabitation projection can be seen in Table 3. The total number of cohabiting couples is projected to rise considerably, from 2.25 million in 2007 to 3.7 million in 2031 . The proportion of the cohabiting population at older ages is expected to become much larger. The number cohabiting at ages 45 to 64 is projected to more than double from nearly 0.5 million in 2007 to more than 1.1 million in 2031 for males, and from nearly 0.4 million to over 1.0 million for females. Large increases are also projected for the over 65 age group, but starting from very low figures in 2007. People currently in this age group would, in the past, have almost always formalised a relationship with marriage.

Thus, whereas in 200725 per cent of male and 19 per cent of female cohabitants were aged over 45 , by 2031 these proportions are projected to rise to 40 per cent for males and 34 per cent for females. 


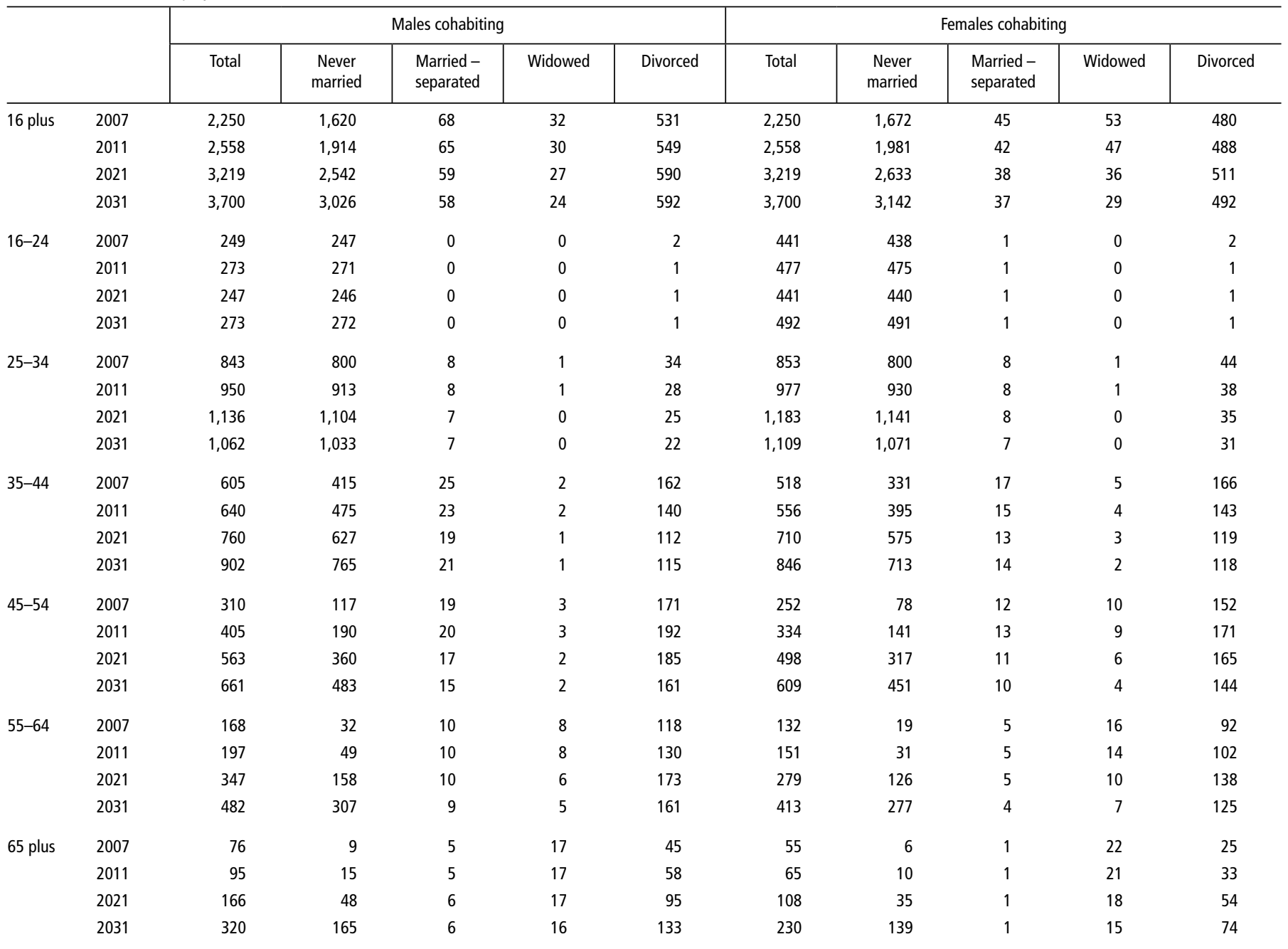

Source: Office for National Statistics

\section{Figure 2}

England and Wales

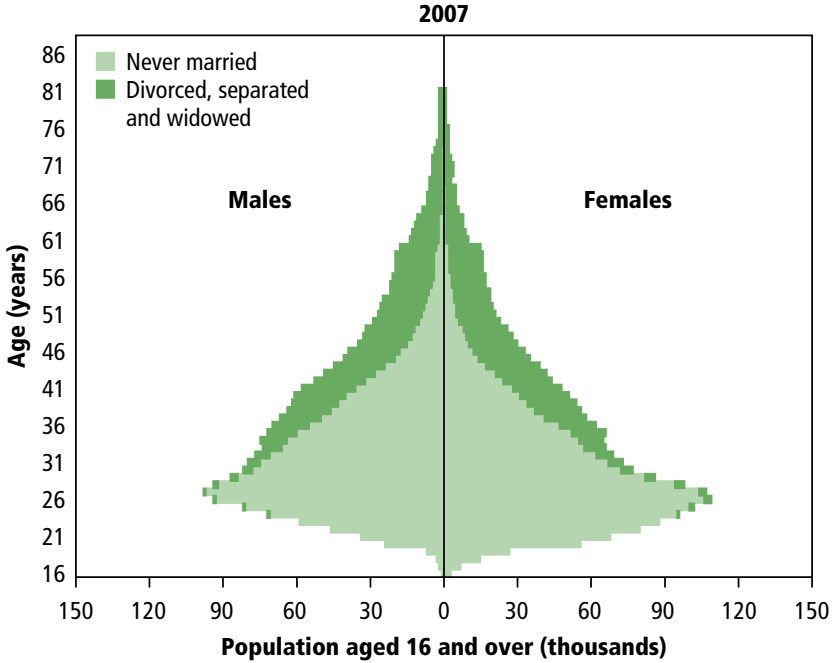

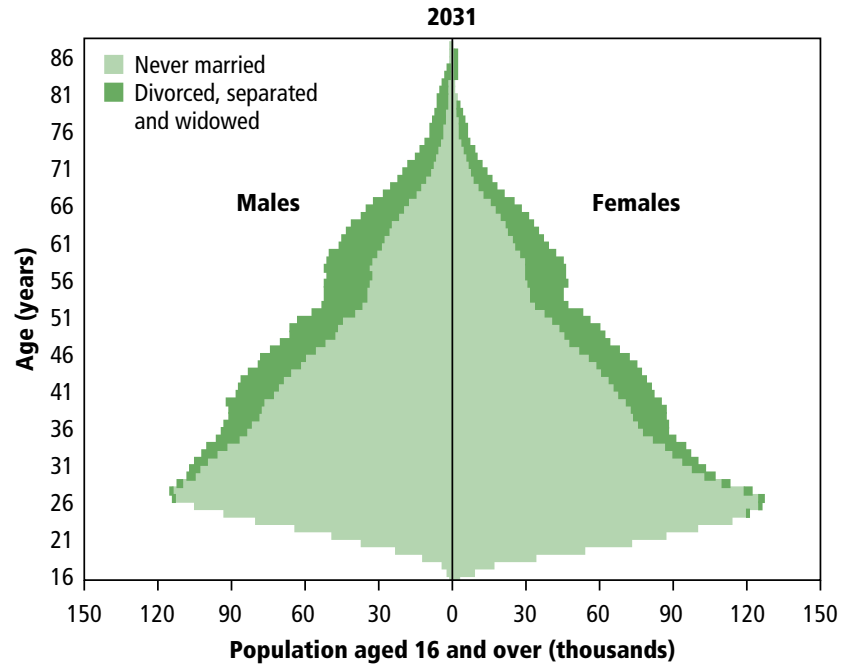

Source: Office for National Statistics 


\section{Table 4}

Comparison of cohabitation variants, 2007 to 2031

England and Wales

2006-based marital status projections

thousands

\begin{tabular}{l|c|c|c|c|c}
\hline \multirow{2}{*}{} & Couples & \multicolumn{4}{|c}{ Persons } \\
\cline { 2 - 6 } & $\begin{array}{c}\text { All } \\
\text { cohabiting }\end{array}$ & $\begin{array}{c}\text { Never } \\
\text { married }\end{array}$ & Separated & Widowed & Divorced \\
\hline Principal projection & & & & & \\
2007 & 2,250 & 3,291 & 113 & 85 & 1,011 \\
2011 & 2,558 & 3,895 & 107 & 77 & 1,037 \\
2021 & 3,219 & 5,175 & 97 & 63 & 1,101 \\
2031 & 3,700 & 6,168 & 95 & 53 & 1,084 \\
High cohabitation variant & & & & & \\
2007 & 2,306 & 3,374 & 115 & 87 & 1,036 \\
2011 & 2,725 & 4,174 & 112 & 81 & 1,084 \\
2021 & 3,766 & 6,151 & 107 & 70 & 1,206 \\
2031 & 4,378 & 7,402 & 104 & 57 & 1,193 \\
Low cohabitation variant & & & & & \\
2007 & 2,194 & 3,210 & 109 & 82 & 986 \\
2011 & 2,391 & 3,615 & 102 & 74 & 990 \\
2021 & 2,672 & 4,201 & 89 & 57 & 996 \\
2031 & 3,022 & 4,935 & 85 & 47 & 976 \\
\hline
\end{tabular}

Note: Figures may not add exactly to totals due to rounding.

Source: Office for National Statistics

The projected cohabitation trends are shown by the pyramids for 2007 and 2031 in Figure 2, which clearly illustrate both the increasing size and the ageing of the cohabiting population (an animated series of population pyramids illustrating the results of the cohabitation projection is available from the ONS website ${ }^{18}$ ).

\section{Variant projections}

As with legal marital status, high and low cohabitation variant projections have also been produced to illustrate the sensitivity of the results to alternative levels of future cohabitation. These variants also allow for some uncertainty in the base estimates of cohabitation by

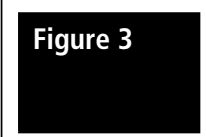

Estimated and projected proportion of population by partnership status and age, 2007 and 2031

England and Wales

$\square$ Cohabiting (opposite-sex couples only) $\square$ Married $\square$ Not living with a partner

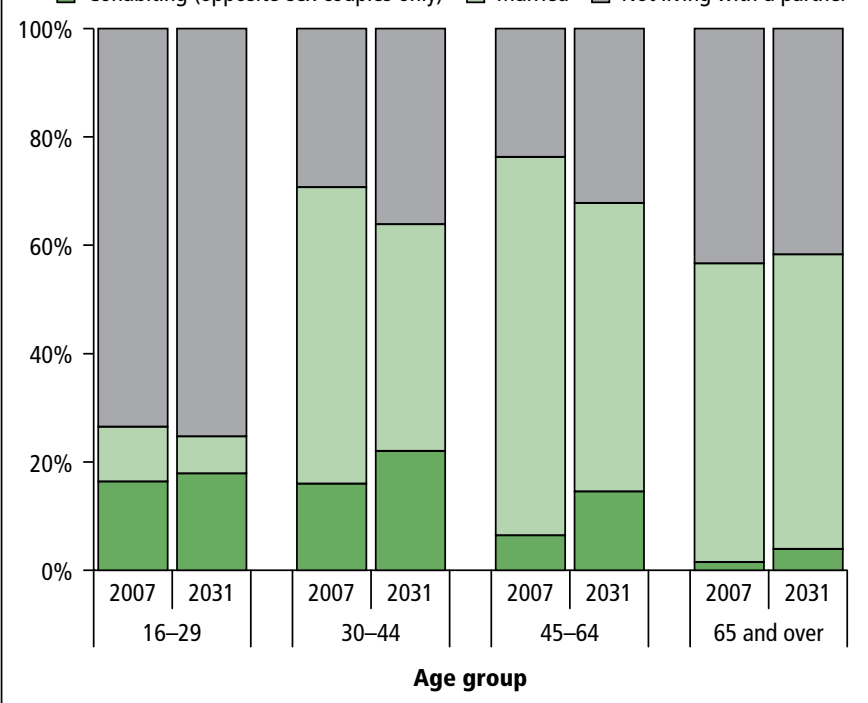

Source: Office for National Statistics varying the initial proportions cohabiting in each age/sex/marital status group by $+/-2.5$ per cent. These revised initial proportions are then assumed to diverge further from the assumed proportions cohabiting in the principal projection, so that from 2022 onwards they differ by $+/-20$ per cent for the never married group and $+/-10$ per cent for the previously married groups. The difference reflects the greater stability of recent trends in proportions cohabiting for previously married groups.

Results of these variant projections can be seen in Table 4. The difference between these variants is considerable, reflecting uncertainty about future cohabitation rates. While there would be 3.7 million cohabiting couples in 2031 under the principal projection assumptions, the number would be as high as 4.4 million for the high cohabitation variant and only 3.0 million for the low cohabitation variant. However, even this low variant represents a 34 per cent increase over the number of cohabiting couples in 2007.

\section{Population by partnership status}

For many users, such as those interested in the demand for housing, it is the combination of the legal marital status projections and the cohabitation projections that is of interest. This is illustrated by Table 5, which looks at future trends in total partnership. This table shows the effect of a smaller proportion of the population becoming married combined with the greater proportion cohabiting, with both trends gradually spreading to older ages.

The proportion of adults who are in co-residential opposite-sex couples is projected to fall, while the proportion of people not living with a partner

\section{Key findings}

- The proportion of the married adult population is projected to fall from 51 per cent in 2007 to 42 per cent in 2031 for males, and from 48 per cent to 41 per cent for females, with corresponding increases in the proportion that never marry

- Recent falls in marriage rates at ages under 30 will, in time, have an impact at older ages. It is projected that there will be marked falls in the married population and increases in the never married population at ages 30 to 64 in the period to 2031

- The proportion of adults who are divorced is expected to continue rising at ages over 65 . At ages 45 to 64 the proportion that is divorced will rise to a peak around 2021 and is then expected to start to fall. At younger ages, the proportion of divorced adults is projected to fall gradually from 2007

- The proportion of females aged 75 and over who are widowed is projected to fall from 61 per cent in 2007 to 40 per cent in 2031, and from 26 per cent to 19 per cent for males. This is largely due to projected improvements in life expectancy

- The number of cohabiting couples, estimated to be 2.25 million in 2007, is projected to increase by almost two-thirds to 3.7 million by 2031 . The proportion of the cohabiting population at older ages is expected to get much larger; in 2007 only 25 per cent of male cohabitants and 19 per cent of female cohabitants were aged over 45, but by 2031 these proportions are projected to rise to 40 per cent for males and 34 per cent for females

- The proportion of adults who are in co-residential opposite-sex couples is projected to fall at most ages, while the proportion of people not living with a partner correspondingly rises. In contrast, the proportion of adults aged over 65 who are married or cohabiting is projected to rise slightly, largely due to projected improvements in life expectancy 


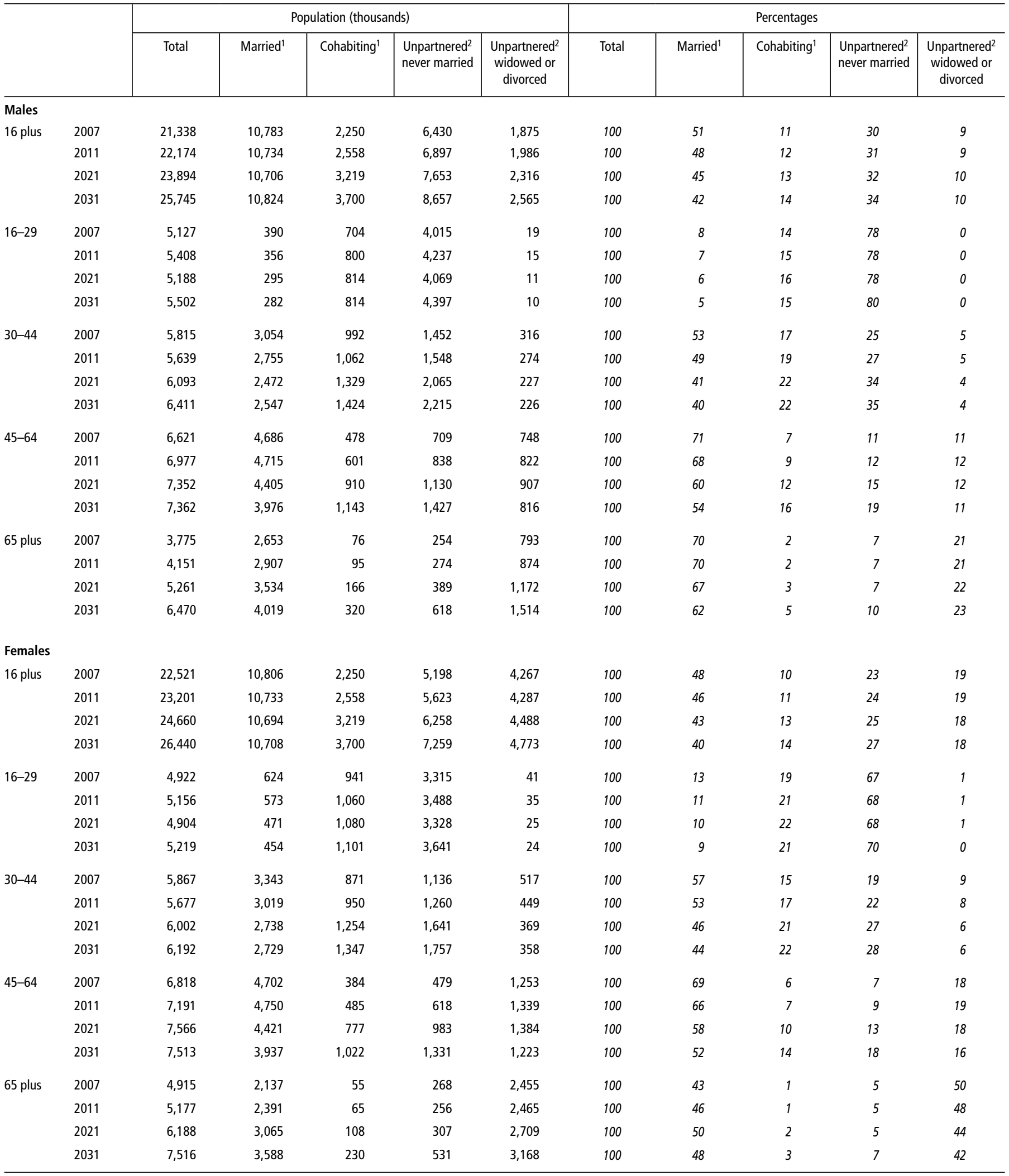

Notes:

1. People who are separated and cohabiting are included in the cohabiting category, and excluded from the married category, in this table. The married category will include people who are separated but not cohabiting; projections are not available for this group.

2. Not living with an opposite-sex partner.

Source: Office for National Statistics 
correspondingly rises at most ages, as illustrated in Figure 3. Only for women aged over 65 is the proportion of the population who are either legally married or cohabiting projected to increase, from 45 per cent in 2007 to 51 per cent in 2031, largely due to projected improvements in life expectancy.

\section{Notes, references and links to downloadable information on this topic}

1 To access full results of the 2006-based marital status projections see: www.statistics.gov.uk/statbase/Product.asp?vlnk=14491

2 Cohabitation estimates and projections are produced for opposite-sex co-residential cohabiting adults only.

3 A variant for marriages abroad was produced for the 2003-based set of marital status projections.

4 To access results of the 2003-based marital status projections see: www.gad.gov.uk/Demography\%20Data/Marital\%20status\%20 projections/

5 For information about the 2006-based national population projections see: www.statistics.gov.uk/StatBase/Product.asp?vlnk=8519

6 For the latest marital status estimates for England and Wales see: www.statistics.gov.uk/statbase/Product.asp?vlnk=15107

7 Wilson B (2009), Estimating the cohabiting population, Population Trends 136.

8 For information on household projections produced by Communities and Local Government see: www.communities.gov. $\mathrm{uk} /$ housing/housingresearch/housingstatistics/housingstatisticsby/ householdestimates/
9 For methodology documentation see: www.statistics.gov.uk/ downloads/theme_population/Marr-proj06/method.pdf

10 For further information on the marriage assumptions see: www.statistics.gov.uk/downloads/theme_population/Marr-proj06/ marriage.pdf

11 For further information on the divorce assumptions see: www.statistics.gov.uk/downloads/theme_population/Marr-proj06/ divorce.pdf

12 For further information on the cohabitation assumptions see: www.statistics.gov.uk/downloads/theme_population/Marr-proj06/ cohabitation.pdf

13 For further information about mortality see: www.statistics.gov.uk/ downloads/theme_population/Marr-proj06/mortality.pdf

14 For further information about migration see: www.statistics.gov.uk/ downloads/theme_population/Marr-proj06/migration.pdf

15 For details of how constraints are handled within the model see: www.statistics.gov.uk/downloads/theme_population/Marr-proj06/ consistency.pdf

16 An adult is defined as a person aged 16 years or older

17 Animated population pyramids, by legal marital status, 2007-2031 see: www.statistics.gov.uk/downloads/theme population/Marrproj06/legalpyramid.pps

18 Animated population pyramids of the cohabiting population, 2007-2031 see: www.statistics.gov.uk/downloads/theme_population/ Marr-proj06/cohabpyramid.pps 